\title{
脳の情報処理と問題解決
}

\section{Information Processing of Brain and Problem Solving}

\author{
福 永 征夫 Masao FUKUNAGA
}

ABSTRACT : To recover the damaged environment and ecosystem of the earth, we should search and discover broader domain knowledge which is common among different domain knowledges, and through it, we should maintain continuity between every diverse activities of human beings to live, that is, we have to let those activities not be inconsistent with each other to economize the amount of resource and energy.

The characteristic of brain's information processing function is maintaining continual understanding and practice to the living environment by the process to realize concurrent optimization of each part and the whole between plural diverse and different domain knowledges in order to discover common broader domain knowledge to put it into practice.

\section{1 . 地球規模の難題への対処}

多様な自然の破壊や自律的な人間の精神の荒廃を伴う地球規模の深刻な問題群に有効に 対処するためには、人間の脳の情報処理の特質を解明することが不可欠である。

省資源・省エネルギーの実を挙げて地球のシステムや生態系の偏芯を回復するためには、 多様で異なる領域的な知による多様な省資源・省エネルギーの営みの間に共通する広域的 な知を発見しなければならない。人間の多様な生産・消費・廃棄の活動を互いに矛盾のな い連続性のあるものとして実現することが重要である。

2 . 省資源・省エネルギーの営みのモデル

省資源・省エネルギーの実を挙げるためには、全ての生産・消費・廃棄の営みが、次の 10 項目の全てに該当する省資源・省エネルギーの営みとして遂行されなければならない。 そのような生産・消費・廃棄の営みを実現するためには、10 項目の省資源・省エネルギー の営みのうちのいずれの 2 つをとっても矛盾なく両立するような広域的な知を発見してい かなければならない。

(1)常に新レベルの有意で高性能な財・サービス・知的システムを新たに開発して資源やエ ネルギーおよび情報の活用効果と利用効率を限りなく高める.

(2)部材の機能の傾斜複合化，財・サービス・知的システムの有意な複合化を図って資源や エネルギーおよび情報の活用効果と利用効率の向上を追求する.

(3)内外の要因に基づくシステムの変動に対し新たな自己組織化によって自律対処のでき る誤作動や故障のない安定品質・長寿命の財・サービス・知的システムを生産し消費す る.

(4)新レベルの高性能パーツとの交換で当初の性能を上回る若返り修理が可能な財・サービ 
ス・知的システムを生産し消費する.

(5)廃物を燃料としてではなく再利用の可能なパーツや素材として，また，残留熱量を再利 用の可能なエネルギー源として，完全に回収し消尽的な循環利用ができるように財・サ ービス・知的システムを生産し消費する。

(6)特定の種類の資源やエネルギーおよび情報の大量使用を抑制し解消するため常に代替 の資源やエネルギーおよび情報を開発し実用化する。

(7)高物質・高エネルギー社会の生産・消費・廃棄における摩擦，抵抗，接合や表面の劣化， 資源・エネルギー・情報の未利用排出, 排気ガス, 騒音, 振動, 粉塵, 過剩照明, によ るムリ・ムラ・ムダの検出と排除の徹底を期して改善と是正を図る.

8環境に修復困難な影響を与えないように財・开ービス・知的システムを生産・消費・廃 棄し，損耗を生じた場合は直ちに修復をし保全を図る。

(9)大気・土壤・海水・河川水・湖沼水・地下水の短期 - 小域かつ長期・大域の成分分析を 通じて人の生産・消費・廃棄の営みと地球のシステムや生態系の偏芯との因果をサベイ ランスし原状回復のための暫定・恒久策の徹底を期する。

(10人体構成成分の短期・小域かつ長期・大域の成分分析を通じて, 地球のシステム・生態 系の偏芯と人体のシステムの偏芯との因果, および衣・食・住・その他の生産・消費・ 廃棄の営みと人体のシステムの偏芯との因果をサベイランスし原状回復のための暫 定・恒久策の徹底を期する。

\section{3 ．脳の機能と情報処理の特質}

（1）脳の機能人の脳の機能は『過去を想起し未来を予期して今ここに対処する』こ とである。人は生存環境との間に生じた不均衡を解消するために、不均衡な事態を理解し 働きかけるのに必要な新たな情報を取り入れる。そして過去を想起し、新たな情報と過去 に蓄積した記憶情報との間の意味の類似と差異を探索する。過去の記憶情報との類似と差 異による類比と外挿を行なって、引き続く未来に生起する事物・事象や自らの思考・自ら の行動を予期する。未来についてのより可能でより確実な予期を選択しながら今ここに対 処している。

（2）脳の情報処理の特質 知・情・意による脳の総合的な情報処理の機能の特質は『多 様で異なる領域的な知の間に、部分と全体の同時最適化を実現して、より広域的な知を発 見し創造して実践に移し、生存環境に対する理解と働きかけの連続性を確保しようとする』 ところにある。

\section{4. 領域的な知と広域的な知}

（1）領域的な知領域的な知とは、特定の分野の目的行動を行なうための理解と働き かけをするのに要した、または要すると思われる知の要素および要素の関係とそれらの集 合のことをいう。

（2）広域的な知広域的な知とは、異なる領域的な知の間に広域的に創発する知のパ ターンのことをいう。知のパターンとは、脳という認知場において、小域で隣接する 3 つ の記憶の部分域、または中域で近接する 3 つの記憶の部分域、または大域で離隔する 3 つ の記憶の部分域が、肯定 $\times$ 否定 $\times$ 否定あるいは肯定 $\times$ 肯定 $\times$ 肯定の関係に収束したときに 創発するところの 2 つの記憶あるいは 3 つの記憶が担う事実や価値や目的の記憶の間の共 通的ないしは類似的な意味のパターンをいう。3つの記憶の部分域の関係を小域的なもの 
から中域的なものや大域的なものに組み換えて、より広域的な知を創発する部分と全体の 同時最適化のプロセスは、『3 軸認知場』のモデルに『部分域と全体域の誘導合致』のモデ ルを適用することによって計算論で示すことができる。

\section{5 .『3 軸認知場』のモデル}

（1）予期と対処が知のモジュールを蓄積人は現在から未来に向けて新たな記憶の部 分域を形成し、事物・事象・自らの思考・自らの行動に関する事実と価值と目的の情報を、 脳という [時間］［事実・目的空間］［評価(感情) 空間］の3 軸からなる認知場に、4 単位 の記憶の部分域が起・承・転・結の順で連なる知のモジュールを積み重ねて蓄積する。領 域的な知は、知のモジュールの集合である。

(2) 時間的な知と空間的な知の交叉 知のモジュールは、時間的な知と空間的な知が 交叉して形成され、時間的な知・空間的な知・時間的な知の連鎖または空間的な知・時間 的な知・空間的な知の連鎖によって成立する。知のモジュールは他の知のモジュールと並 存したり、より上位の知のモジュールの構成単位となる。時間的な知とは、時間軸で隣接 する独立事象の記憶と従属事象の記憶からなる一対の事実または価值または目的の記憶が 空間軸の同じ位置に蓄積されたものをいう。空間的な知とは、空間軸で隣接する独立事象 の記憶と独立事象の記憶からなる一対の事実または価値または目的の記憶が時間軸の同じ 位置に蓄積されたものをいう。

(3) 想起が広域的な知を創発脳は現在から過去に向けて新たな記憶の部分域から過 去の記憶の全ての部分域へエネルギーや物質を循環させ、新たな記憶の部分域と過去の記 憶の全ての部分域を融合という関係で結びつけて、記憶の過去の全てのネットワークと多 重させながら、記憶の最新のネットワークを構築する。このプロセスで、3つの記憶の部 分域の関係が小域的なものから中域的なものや大域的なものに組み換えられて、より脱領 域的で、より広域的な知が創発する。

\section{6 . 部分と全体の同時最適化}

\section{（1）エネルギー・物質の系}

自然のシステムがエネルギーや物質量のレベルの高い部分域から低い部分域へエネルギー や物質を循環させるプロセスにおいて、部分域同士は、ある側面でプラスに関係しエネル ギーや物質の移動を促進し合うと共に他の側面ではマイナスに関係してエネルギーや物質 の移動を抑制し合い、トータルでは両方の関係が平均されてプラスでもマイナスでもない 中立的な『融合』の関係で結合して、部分と全体の同時最適化を実現する。

\section{（2）情報の系}

エネルギーや物質の系としての脳の記憶の部分域 A と B がプラスに関係するとき、情報の 系としての脳では、記憶の部分域 A と B が担う事実または価值または目的の情報が肯定し 合って共通的・類似的な意味が見出され、マイナスに関係するときは、否定し合って各々 の個別的・差異的な意味が見出される。そして、今ここにおける有意な方の関係が選択さ れて顕在化する。

新たな記憶情報と過去の記憶情報との共通性・類似性や個別性・差異性が探索されると きに新たな記憶の部分域 $\mathrm{A} の$ 記憶情報と過去の記憶の部分域 $\mathrm{B}$ の記憶情報との 2 者関係に おいて、肯定ないしは否定の有意な方の関係が選択されるという部分の最適化と、記憶の 部分域 $\mathrm{A} ・$ 記憶の部分域 $\mathrm{B} ・ \mathrm{~B} よ り も$ 過去の記憶の部分域 $\mathrm{C}$ の 3 者の記憶情報の関係にお 
いて、否定 $\times$ 否定 $\times$ 否定の関係の組み合わせや肯定 $\times$ 肯定 $\times$ 否定の関係の組み合わせの不 安定な関係よりも、肯定 $\times$ 否定 $\times$ 否定の関係の組み合わせ、または、肯定 $\times$ 肯定 $\times$ 肯定の 関係の組み合わせの安定な関係が選好されるという全体の最適化が同時に実現するように、 脳という認知場が組織化されて、脱領域的で広域的な知が創発する。

\section{7. 想起が広域的な知を創発するプロセスのモデル}

脳が新たな記憶の部分域と過去の記憶の全ての部分域を『融合』させて、記憶の最新のネ ットワークを構築すると共に、より脱領域的でより広域的な知を創発するプロセスは、『部 分域と全体域の誘導合致』のモデルによって計算論で示すことができる。

\section{8.『部分域と全体域の誘導合致』のモデル}

\section{(1) モデル式}

自然のシステムがエネルギーや物質量のレベルの高い部分域 $\mathrm{P}_{2}$ から低い部分域 $\mathrm{P}_{1}$ ヘエネ ルギーや物質を循環させるプロセスにおいて、 $\mathrm{P}_{2}$ と $\mathrm{P}_{1}$ は、ある側面でプラスに関係しエ ネルギーや物質の移動を促進しあうと共に他の側面ではマイナスに関係してエネルギーや 物質の移動を抑制し合い、トータルでは両方の関倸が平均されてプラスでもマイナスでも ない中立的な『融合』の関係で結合し、エネルギーや物質の系の部分と全体の同時最適化 を実現する。

$\mathrm{P}_{2}, \mathrm{P}_{1}$ のエネルギーや物質量のレベルを $\ell \mathrm{P}_{2}, \mathrm{lP}_{1}\left[\mathrm{lP}_{2}>\ell \mathrm{P}_{1}>0\right]$ とし、 $\mathrm{CP}_{2}=1$ とした ときの $\mathrm{QP}_{2}$ と $\mathrm{PP}_{1}$ の比を、

$$
\mathrm{QP}_{2} / \mathrm{eP}_{1}=1 / \mathrm{\ell} \mathrm{P}_{1} \quad \text { 【 } 1 \text { 】 }
$$

のように表わすと、 $\mathrm{P}_{2}$ と $\mathrm{P}_{1}$ の間のプラ

スの関係は、

$$
\ell \mathrm{P}_{2} / \ell \mathrm{P}_{1}>\ell \mathrm{P}_{2}+\ell \mathrm{P}_{1}
$$

$\mathrm{P}_{2}$ と $\mathrm{P}_{1}$ の間のマイナスの関係は

$$
\ell \mathrm{P}_{2} / \ell \mathrm{P}_{1}<\ell \mathrm{P}_{2}+\ell \mathrm{P}_{1} \quad \text { 【 } 3 \text { 】 }
$$

$\mathrm{P}_{2}$ と $\mathrm{P}_{1}$ の間のトータルとしての中立的な『融合』の関係は、

$$
\ell \mathrm{P}_{2} / \ell \mathrm{P}_{1}=\ell \mathrm{P}_{2}+\ell \mathrm{P}_{1} \quad \text { 【4 }
$$

というモデル式で表わされる。

( 2 ） モデル項

1 つの全体域になろうとする作用の力は、 $\mathrm{eP} \mathrm{P}_{2}$ と $\mathrm{lP}{ }_{1}$ の格差が大きくなる程に強くなり、格 差が小さくなる程に弱くなる。

$\ell \mathrm{P}_{2} / \ell \mathrm{P}_{1}$ の項の值は、 $\ell \mathrm{P}_{1}$ が小さくなれば増加し、 $\ell \mathrm{P}_{1}$ が大きくなれば減少するので、 $\ell \mathrm{P}_{2} / \ell \mathrm{P}_{1}$ の項を、1つの全体域になろうとする作用の力を表わすモデル項とすることがで きる。

各々の部分域のままで留まろうとする作用の力は、 $\ell \mathrm{P}_{2}$ と $\mathrm{lP} \mathrm{P}_{1}$ の格差が小さくなるほどに 強くなり格差が大きくなるほどに弱くなる。 $\ell \mathrm{P}_{2}+\ell \mathrm{P}_{1}$ の項の值は、 $\ell \mathrm{P}_{1}$ が大きくなれば増加し、 $\mathrm{QP} \mathrm{P}_{1}$ が小さくなれば減少するので、 $l \mathrm{P}_{2}+\mathrm{e} \mathrm{P}_{1}$ の項を、各々の部分域のままで留まろうとする作用の力を表わすモデル項とする ことができる。

（ 3 ）モデル式の解

【1】と【2】からプラスの関係のモデル式の解は、 $\ell \mathrm{P}_{1}<(\sqrt{5}-1) / 2$ となり、【1】 
情報知識学会誌 Vol. 16, No. 2

と【3】からマイナスの関係のモデル式の解は、 $\ell P_{1}>(\sqrt{ } 5-1) / 2$ となる。【1】と

【4】から『融合』の関係のモデル式の解は、 $\ell P_{1}=(\sqrt{ } 5-1) / 2$ となる。

\section{(4)『融合定数』と『循環定数』}

自然のシステムにおいて、エネルギーや物質量のレベルが高い部分域から低い部分域へ順 次にエネルギーや物質を循環させて、それらの全ての部分域が多重なネットワークとして 融合の関係で結びっくためには、

《 $\left.1 》 \quad \ell \mathrm{P}_{2} / \ell \mathrm{P}_{1}=1 /\{(\sqrt{5}-1) / 2\}\right\}$ を満たすことのほかに、

《2》 $\mathrm{P}_{2}$ から $\mathrm{P}_{1}$ 移動するエネルギーや物質量のレベルが、

$$
\sqrt{ }\{(\sqrt{5}-1) / 2\}-(\sqrt{5}-1) / 2 \text { に相当すること、 }
$$

という2つの条件を満たさなければならないことを、『知の組み換えの基本モジュール』の 例によって、計算論で示すことができる。

$[(\sqrt{5}-1) / 2 \doteqdot 0.61803398]$ を『融合定数』F S [FUSIONAL CONSTANT] と名づけ、 $[\sqrt{ }\{(\sqrt{5}-1) / 2\}-(\sqrt{5}-1) / 2 \doteqdot 0.168117389]$ を『循環定数』C R [CIRCULATIVE CONSTANT] と名づけることにすると、Ｆ S と C R の間には、

$$
(\mathrm{F} \mathrm{S}+\mathrm{CR})^{2}=\mathrm{F} \mathrm{S} \text { という関係が存在する。 }
$$

\section{9.『知の組み換えの基本モジュール』}

基本モジュールは図のように現在から未来に向けて形成される 6 個の記憶の部分域 $\mathrm{F}$, $\mathrm{G}, \mathrm{H}, \mathrm{I}, \mathrm{J}, \mathrm{K}$ からる。

F G， H I，J Kの結びつきは時間的な知であり、G H， I J の結びつきは空間的な知 である。

それぞれの部分域の間が肯定の関係の場合は実線、否定の関係の場合は点線で表わされ る。

新たな記憶の部分域 Kから過去の記憶の部分域 J , I , H, G, Fヘエネルギーや物質 を循環させて融合の関係で結合させ、3 組の記憶の関係を K J I という小域的なものから K I H という中域的なものやKHGという大域的なものに組み換えて、KHGというより 広域的な知のパターンを創発するプロセスの基本モジュールを 10 ステップで記述するこ とができる。

[1] エネルギー・物質量の大きさが $\mathrm{x}$ の $\mathrm{K}$ とネルギー・物質量の大きさが $\mathrm{F} \mathrm{S} \times \mathrm{x}$ の

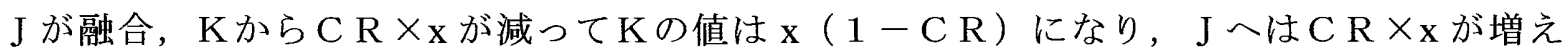
て J の值は $\mathrm{x}$ (F S + C R ) になる.

この表現を略して，K[x]と $\mathrm{J}[\mathrm{FS} \times \mathrm{x}]$ が融合，Kは $\mathrm{K}[\mathrm{x}(1-\mathrm{CR})] に ， \mathrm{~J}$ は $\mathrm{x}(\mathrm{FS}+\mathrm{CR})]$ なる，と 記すこととし，[2]からは略記による。K J は肯定の関係であると仮定.

[2] J $[\mathrm{x}(\mathrm{FS}+\mathrm{CR})]$ と I $[\mathrm{FS} \times \mathrm{x}(\mathrm{FS}+\mathrm{CR})]$ が融合，Jは $\mathrm{J}(\mathrm{FS}+\mathrm{CR})(1-\mathrm{CR})]$ に I は $\left[\mathrm{x}(\mathrm{FS}+\mathrm{CR})^{2}\right]$ になる．J I は否定の関係であると仮定.

[ 3 ] I $\left[\mathrm{x}(\mathrm{FS}+\mathrm{CR})^{2}\right]$ と $\mathrm{H}\left[\mathrm{FS} \times \mathrm{x}(\mathrm{FS}+\mathrm{CR})^{2}\right]$ が融合，I は $\left[\mathrm{x}(\mathrm{FS}+\mathrm{CR})^{2}(1-\mathrm{CR})\right]$ に, $\mathrm{H}$ は $\left[\mathrm{x}(\mathrm{FS}+\mathrm{CR})^{3}\right]$ になる。 I H は否定の関係であると仮定.

[4] K $[\mathrm{x}(1-\mathrm{CR})]$ と I $\left[\mathrm{x}(\mathrm{FS}+\mathrm{CR})^{2}(1-\mathrm{CR})\right]$ が融合，Kは $\mathrm{K}\left[\mathrm{x}(1-\mathrm{CR})^{2}\right] に ， \mathrm{I}$ は $[\mathrm{x}(1-\mathrm{CR})(\mathrm{FS}+\mathrm{CR})]$ になる．KI は否定の関係となる。

[ 5 ] I $[x(1-C R)(F S+C R)]$ と $[\mathrm{FS} \times x(1-C R)(F S+C R)]$ が融合，Iは $\left[x(1-C R)^{2}(F-C+C R)\right]$ 
に, $\mathrm{H}$ は $\left[\mathrm{x}(1-\mathrm{CR})(\mathrm{FS}+\mathrm{CR})^{2}\right]$ なる．Ｉ Hは否定の関係であると仮定.

なお， [ 3 ] における $\mathrm{H}$ の $\left[\mathrm{x}(\mathrm{FS}+\mathrm{CR})^{3}\right]$ は，Hを新たな記憶の部分域とする過去のネットワ 一クに循環し，それを活性化する。

[ 6$] \mathrm{H}\left[\mathrm{x}(1-\mathrm{CR})(\mathrm{FS}+\mathrm{CR})^{2}\right]$ と $\mathrm{G}\left[\mathrm{FS} \times \mathrm{x}(1-\mathrm{CR})(\mathrm{FS}+\mathrm{CR})^{2}\right]$ が融合, $\mathrm{H}$ は $\left[\mathrm{x}(1-\mathrm{CR})^{2}(\mathrm{FS}+\mathrm{CR})^{2}\right]$, Gは $\left[x(1-C R)(F S+C R)^{3}\right]$ になる.HGは肯定の関係であると仮定.

[ 7$] \mathrm{K}\left[\mathrm{x}(1-\mathrm{CR})^{2}\right]$ と $\mathrm{H}\left[\mathrm{x}(1-\mathrm{CR})^{2}(\mathrm{FS}+\mathrm{CR})^{2}\right]$ が融合, $\mathrm{K}$ は $\left[\mathrm{x}(1-\mathrm{CR})^{3}\right]$ に $\mathrm{H}$ は $\left[\mathrm{x}(1-\mathrm{CR})^{2}(\mathrm{FS}+\mathrm{CR})\right]$ になる. K H は肯定の関係となる.

[ 8$] \mathrm{H}\left[\mathrm{x}(1-\mathrm{CR})^{2}(\mathrm{FS}+\mathrm{CR})\right]$ と $\mathrm{G}\left[\mathrm{FS} \times \mathrm{x}(1-\mathrm{CR})^{2}(\mathrm{FS}+\mathrm{CR})\right]$ が融合, $\mathrm{H}$ は $\left[\mathrm{x}(1-\mathrm{CR})^{3}(\mathrm{FS}+\mathrm{CR})\right]$, $\mathrm{G}$ は $\left[\mathrm{x}(1-\mathrm{CR})^{2}(\mathrm{FS}+\mathrm{CR})^{2}\right]$ になる. H G は肯定の関係であると仮定.

なお， [6]における Gの $\left[\mathrm{x}(1-\mathrm{CR})(\mathrm{FS}+\mathrm{CR})^{3}\right]$ は， Gを新たな記憶の部分域とする過去の ネットワークに循環し，それを活性化する。

[9] $\mathrm{G}\left[\mathrm{x}(1-\mathrm{CR})^{2}(\mathrm{FS}+\mathrm{CR})^{2}\right]$ と $\mathrm{F}\left[\mathrm{FS} \times \mathrm{x}(1-\mathrm{CR})^{2}(\mathrm{FS}+\mathrm{CR})^{2}\right]$ が融合, G は $\left[x(1-\mathrm{CR})^{3}(\mathrm{FS}+\mathrm{CR})^{2}\right]$ に， F は $\left[\mathrm{x}(1-\mathrm{CR})^{2}(\mathrm{FS}+\mathrm{CR})^{3}\right]$ にな。 $\mathrm{GF}$ は肯定の関係であると仮定。

$[\mathbf{1 0}] \mathrm{K}\left[\mathrm{x}(1-\mathrm{CR})^{3}\right]$ と $\mathrm{G}\left[\mathrm{x}(1-\mathrm{CR})^{3}(\mathrm{FS}+\mathrm{CR})^{2}\right]$ が融合, $\mathrm{K}$ は $\left[\mathrm{x}(1-\mathrm{CR})^{4}\right]$ に, G は $\left[\mathrm{x}(1-\mathrm{CR})^{3}(\mathrm{FS}+\mathrm{CR})\right]$ になる，K G は肯定の関係となり，K H G という肯定 $\times$ 肯定 $\times$ 肯定の知のパターンが創発 する。

以上のように、[4]において 3 組の記憶の小域的な関係 K J I が成立し、［7］では 3 組 の記憶の中域的な関係 K I Hに組み換えられ、更に $[10]$ で 3 組の記憶の大域的な関係 K H G に組み換えられて、より広域的な知のパターンがコヒーレントに創発するプロセスを 通じ、新たな記憶の部分域 $\mathrm{K} か ゙$ 近接または離隔する全ての記憶の部分域と 4 次のパスで結 合することを確認できる。

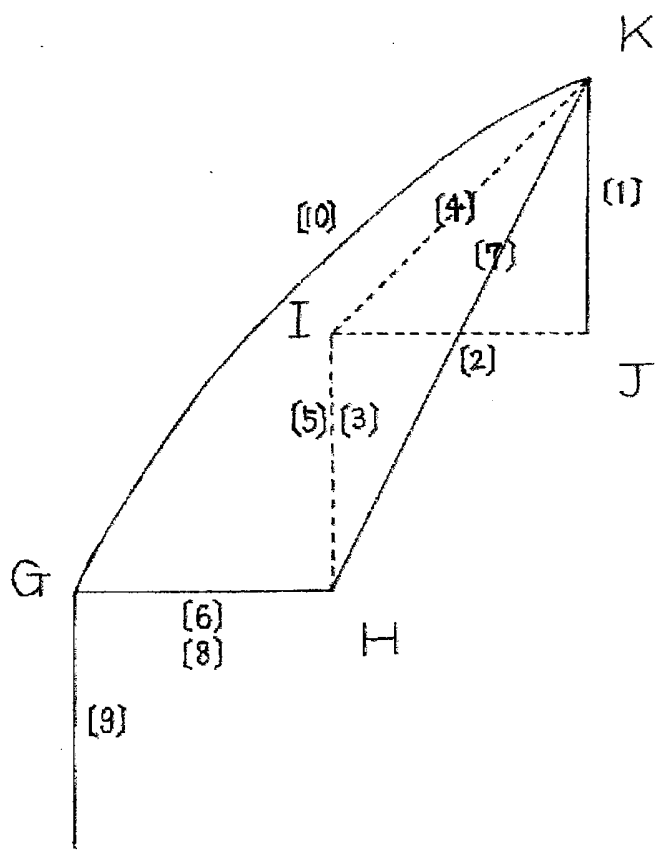

